\title{
NUCLEAR HERNIATIONS OF THE INTERVERTEBRAL DISC
}

\section{Their Radiological Manifestations and Significance}

\author{
A. ('. Begg, I)tNeid, New ZealaNi)
}

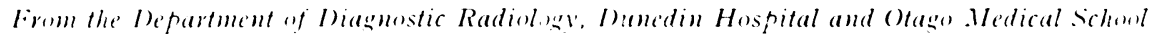

$$
\begin{array}{r}
\text { "And so, from hour to hour, we ripe and ripe, } \\
\text { And the'n from hour to hour, we rot and rot." } \\
\text { Shakespeare }
\end{array}
$$

There is perhaps no structure in the body that reflects the ageing process so early, so often, or to such a marked degree as does the intervertebral disc of the spine. This premature senescence, often advanced by the end of the third decade, together with the tremendous forces which bear upon the intervertebral disc, often causes the nucleus pulposus to herniate through its confining structures - the annulus fibrosus circumferentially and the cartilage

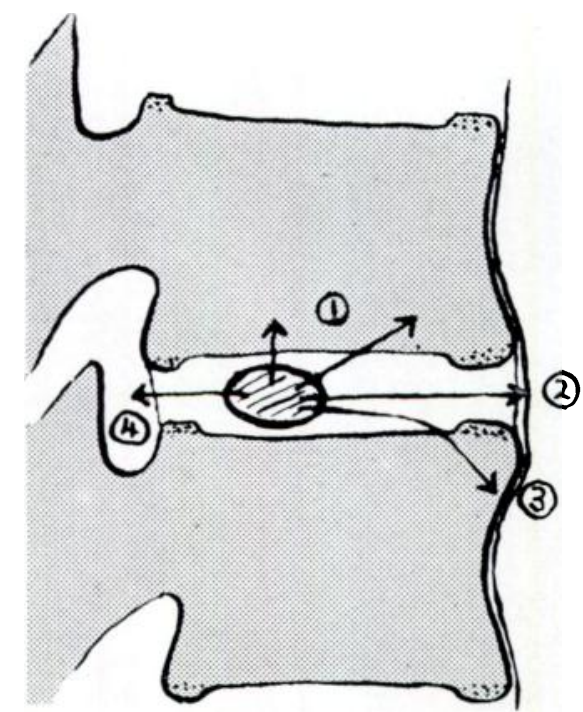

FIG. 1

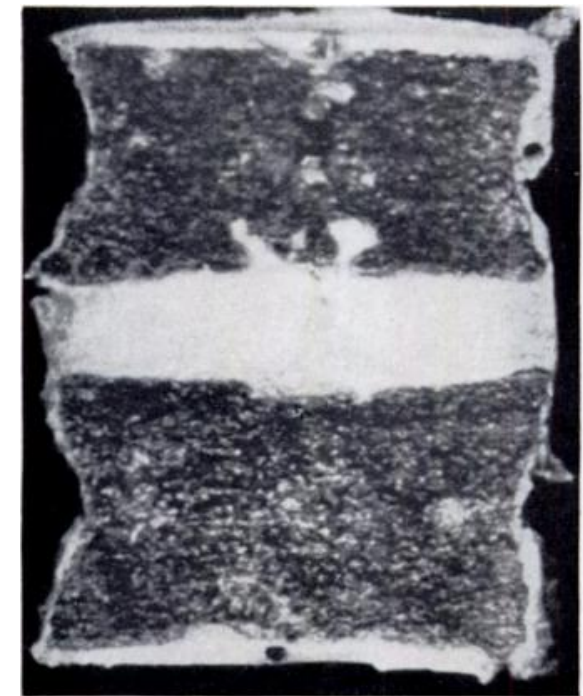

FIG. 2

Figure 1-I)iagram showing the different directions taken by herniations of the nucleus pulposus. Figure 2-Section of lumbar spine showing typical mushroom-shaped nuclear herniation into the centrum.

plates above and below (Fig. 1). These different types of nuclear herniation result in a different clinical and radiological picture and often lead to difficulty in diagnosis. Radiology offers the best, and sometimes the only, method of examining these lesions during life.

It is the purpose of this communication to indicate briefly the significance of the radiological appearances resulting from extrusions of nuclear tissue from the degenerating intervertebral disc.

\section{HERNIATION OF THE NUGLEUS PULPOSUS INTO THE SPONGIOSA} OF THE VERTEBRAL BODY

A frequent finding at autopsy is a cartilaginous nodule lying in the spongiosa of the vertebral body just behind its centre, and arising by a narrow pedicle from the nucleus 
pulposus which has passed through a tear in the thinnest part of the cartilage plate (Fig. : $)$. These mushroom-shaped extrusions of nuclear tissue, or Schmorl's nodes, are not detected radiologically until a thin layer of compact bone has been laid down around them (Fig. 3).

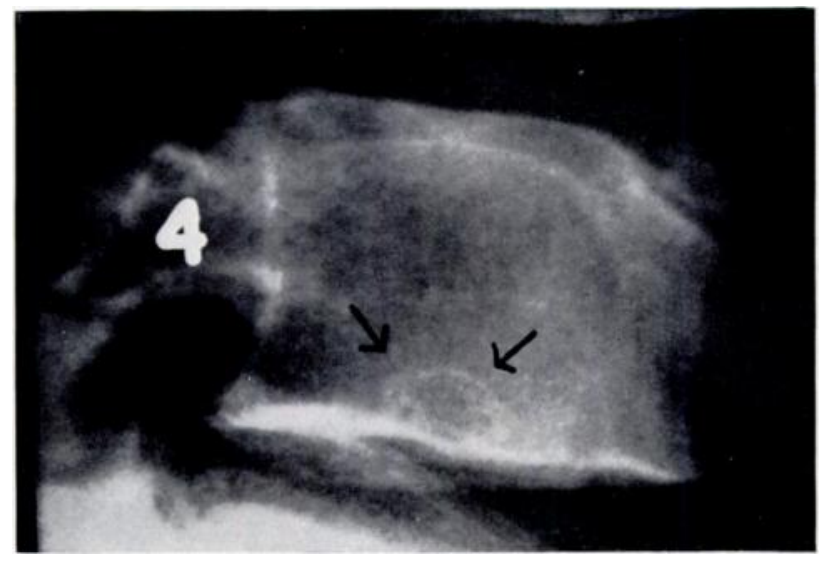

FIG. 3

Lateral radiograph of lower lumbar spine in man aged thirty-six vears, showing thin layer of cortical bone round central nuclear herniation.

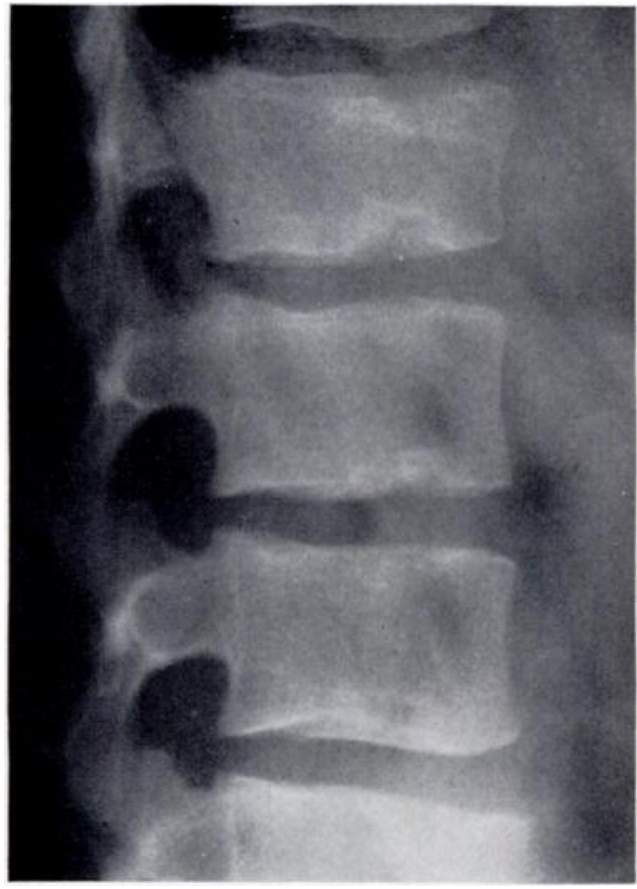

Fig. 4

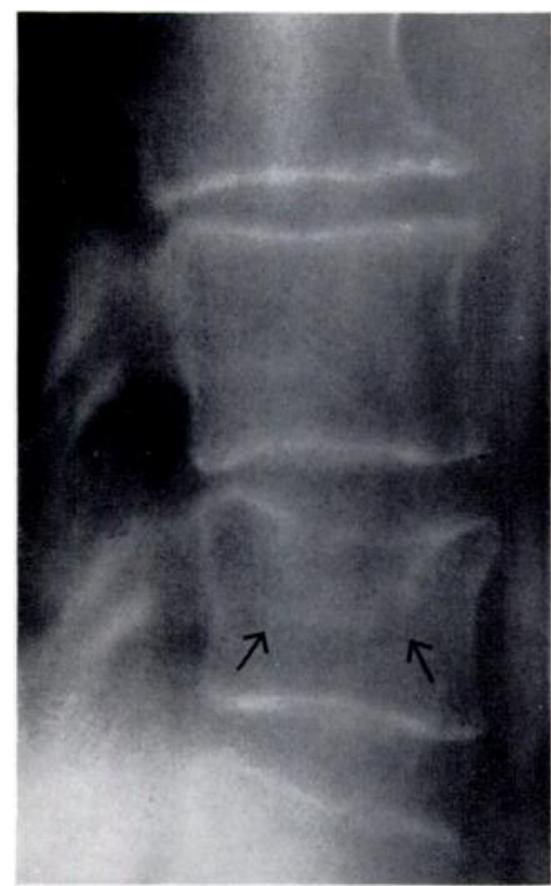

FIG. 5

Figure 4-Lateral radiograph of lumbar spine in man aged thirty years, showing eccentric intraspongy nuclear herniations. Figure 5-Lateral tomograph of lumbar spine in man aged sixty-seven years, showing large herniations of the nucleus pulposus into the centrum of L.4.

This important feature distinguishes them from inflammatory and neoplastic disease of the centrum. They occur chiefly in the thoracic and lumbar spine. They may burrow into more peripheral parts of the centrum (Fig. 4), and may be of considerable size (Fig. 5).

vol. $36 \mathrm{~B}$, No. 2, MAY 1954 


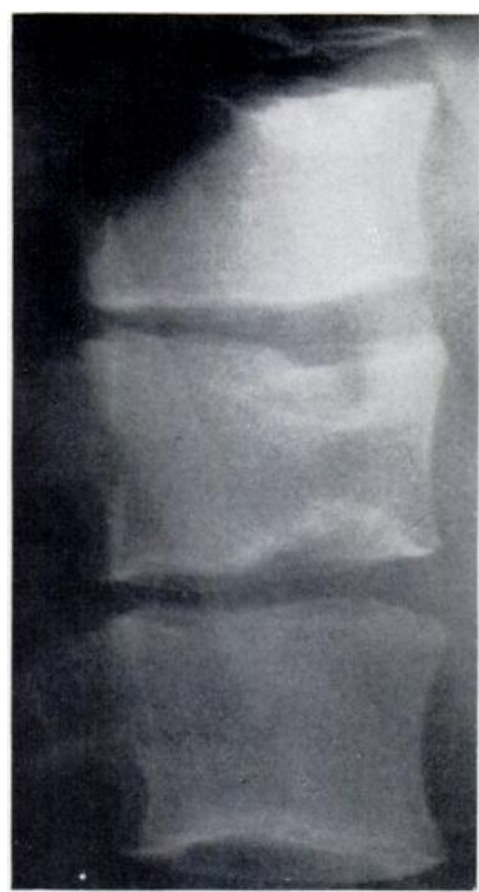

FIG. 6

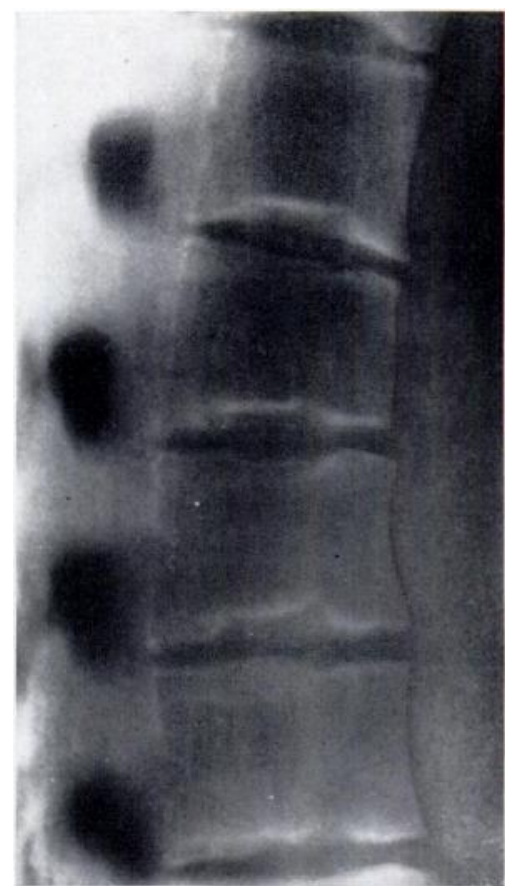

Fig. 7

Figure 6-Lateral radiograph of the upper lumbar spine of man aged thirty-three years, showing evidence of healed osteochondritis with accompanying nuclear herniations into the centra. Figure 7-Lateral tomograph of thoracic spine of man aged twenty-seven years, showing central nuclear herniations with evidence of healed " osteochondritis" involving T.8.

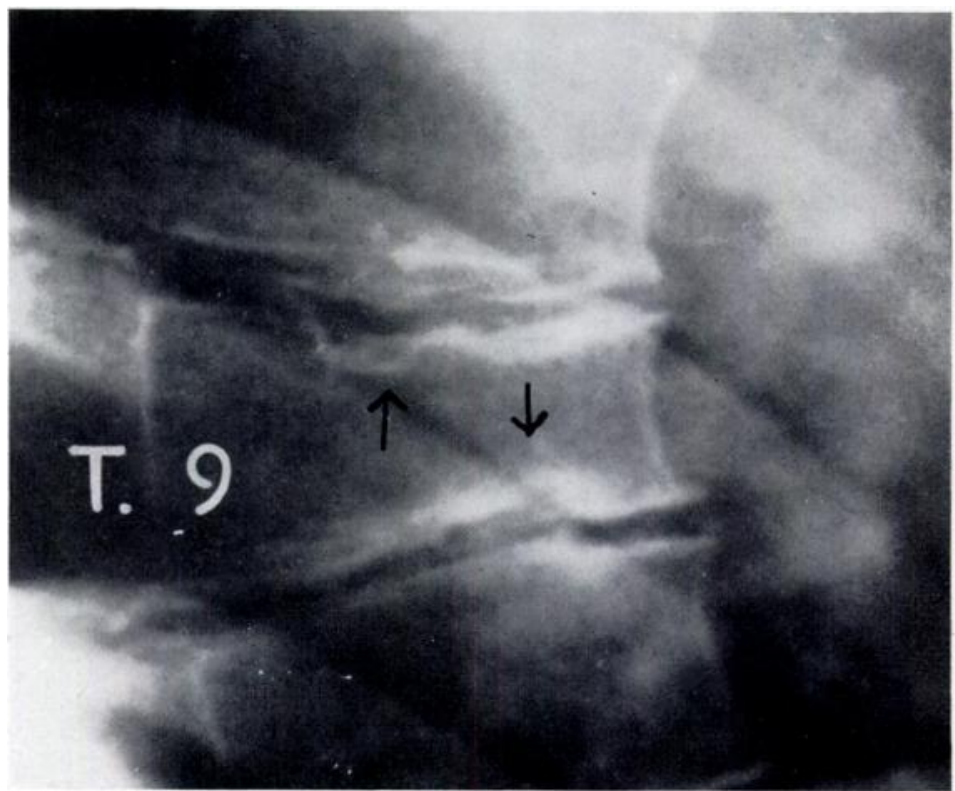

FIG. 8

Lateral radiograph of the thoracic spine of man aged twenty-five years, showing typical healed Scheuermann's disease in T.9, with nuclear herniations into different parts of the vertebral body: 


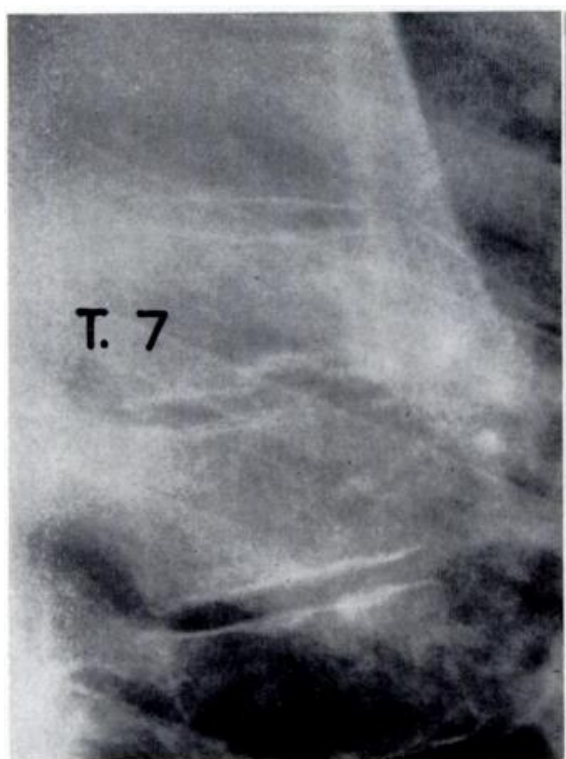

FIG. 9

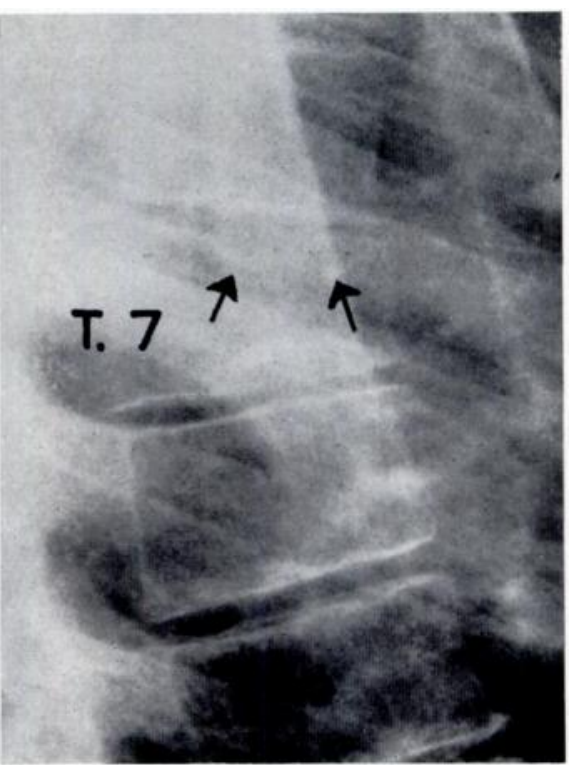

Fig. 10

Figure 9-Lateral radiograph of thoracic spine of man aged thirty vears, showing nuclear herniations into the inferior portion of the centrum of T.7. Figure 10-Four years later the herniations were shown increased in size. A further herniation has developed into the upper portion of the vertebral body, which has collapsed.

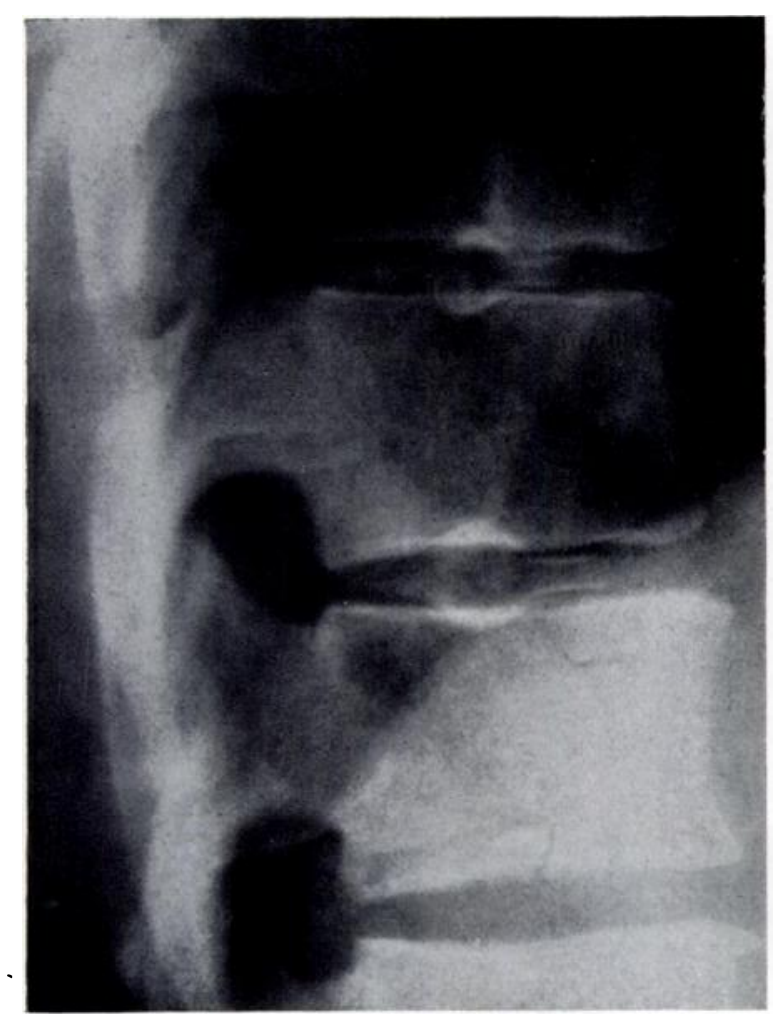

FIG. 11

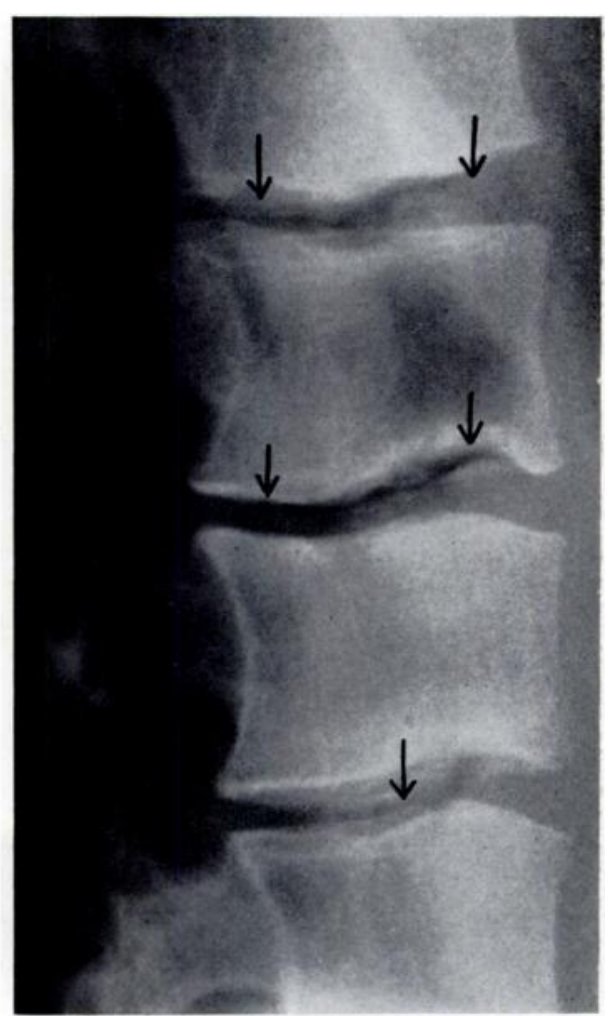

FIG. 12

Figure 11-Lateral radiograph of lower thoracic spine in man aged thirty-five years, showing calcified nuclear tissue extruding along radial cracks in the degenerated discs. Figure 12-Lateral radiograph of lumbar spine in man aged sixty-five years, demonstrating the cracks in the degenerated intervertebral disc by means of gas--the "vacuum phenomenon."

VOL. 36 B, NO. 2, MAY 1954 
In adolescents, Schmorl's nodes are frequently seen in the lower thoracic and upper lumbar spine. They are probably caused by a congenital weakness of the cartilage plate at the site of the notochordal canal, or by scarring of the degenerated blood vessels which supply the juvenile disc. As a result of the loss of nuclear tissue, the function of the disc is impaired, and stresses are no longer distributed evenly over the opposing vertebral surfaces. Pressure is greatest over the anterior aspect of the developing epiphysial ring-its posterior surface is protected by the articular joints-which retards its development and leads to the typical kyphos of adolescent kyphosis or Scheuermann's disease. The characteristic radiological picture with the wedge-shaped vertebral bodies is familiar both in the lower thoracic spine and upper lumbar spine (Fig. 6). Nuclear herniations may be seen in all these cases, although tomography may be required to demonstrate them. Sometimes they occur centrally (Fig. 7) ; sometimes the herniation takes place adjacent to the developing epiphysial ring (Fig. 8).

In later life these herniations are the result of degenerative changes; only a proportion of them are visible radiologically and many do not appear to cause symptoms. Sometimes, however, symptoms appear to arise directly as a result of these nuclear herniations, as in the following case.

A man, aged thirty years, complained of periodic episodes of pain radiating around the thorax, just below the level of the nipple. This was accompanied by stiffness and, latterly, by a curvature of the spine. Twice during three years he was investigated for a large tumour in his right lower chest, which proved to be a mass of liver tissue, and during this time nuclear herniations into the body of the seventh thoracic vertebra were seen to extend and the vertebra to collapse (Figs. 9 and 10 ). Symptoms were relieved by a spinal brace.

\section{HERNIATION OF THE NUCLEUS PULPOSUS THROUGH THE ANTERIOR PART OF THE ANNULUS}

As degeneration proceeds, nuclear material may extrude along the radial cracks which develop in the disc. Its track may be followed radiologically if it calcifies (Fig. 11), or the

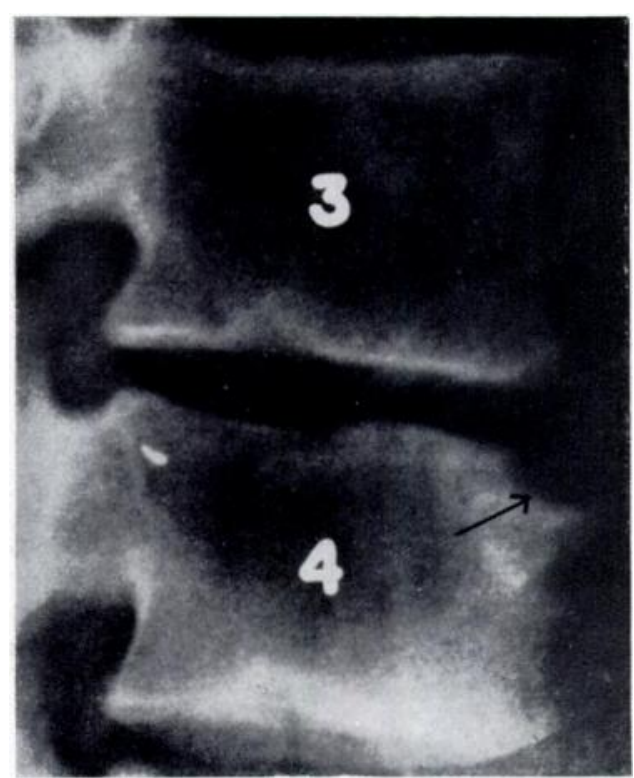

FIG. 13

Lateral radiograph of the lumbar spine in man aged twenty-eight years, showing erosion of the antero-superior margin of L.4 vertebral body by anterior nuclear herniation. site of the annular tears may be demonstrated by the "vacuum phenomenon" (Fig. 12). It is presumed that under the influence of longitudinal strains tending to separate the adjacent vertebral bodies as in hyperextension of the spine, the gases in solution in the degenerated disc tissue are liberated and may be demonstrated lying within the disorganised disc. When the tension is removed, the gas disappears. As the nuclear tissue passes forwards it may broach the anterior fibres of the annulus to impinge upon the tough anterior longitudinal ligament which usually deflects it to cause an erosion of the anterior border of the centrum (Fig. 13). Coventry, Ghormley and Kernohan (1945) described the pathological appearances of such an anterior nuclear herniation which Batts (1939) found in 6 per cent of the fifty spinal columns he examined. These lesions may cause pain in the back and may easily be mistaken for inflammatory or tuberculous disease.

Such anterior protrusions reach their greatest size in some types of dyschondroplasia where 


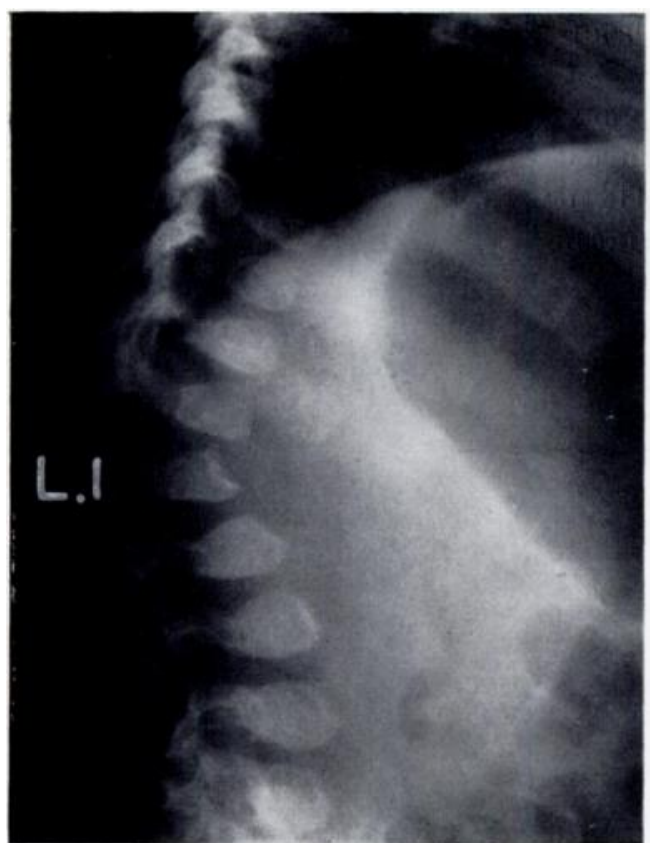

FIG. 14

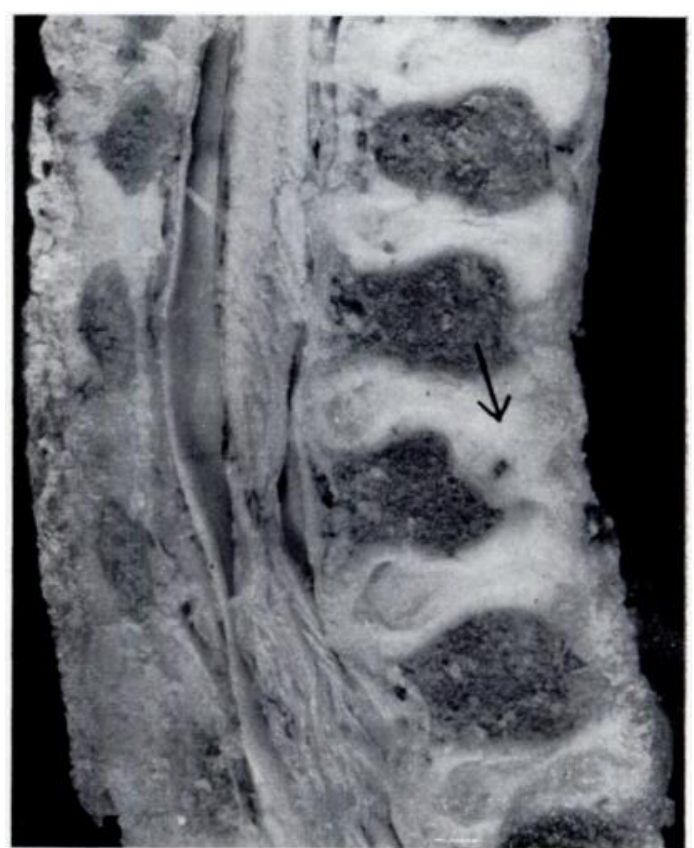

FIG. 15

Figure 14-Lateral radiograph of thoracic and lumbar spine in boy aged six years with chondrodystroph. (Hurler type), showing typical abnormality of L.1 centrum. Figure 15-Sagittal section of spine at thoracolumbar junction, showing that the abnormality is due to an anterior herniation of the nucleus pulposus.

they cause a characteristic erosion of the centrum (Fig. 14). The forward extrusion of nuclear tissue is well seen in this patient - a boy who died at the age of six years suffering from chondro-osteodystrophy of the Hurler type (Fig. 15).

Sometimes the degenerating disc tissue gradually spreads radially, pushing the thinned fibres of the annulus fibrosus before it (Fig. 16) and, as osteophytes grow in response to the additional periosteal stimulation of the unnaturally mobile vertebral bodies, the well known radiological appearances seen in Figure 17 are produced.

\section{HERNIATION OF THE NUCLEUS PULPOSUS BENEATH THE EPIPHYSIAL RING}

Although these lesions may occur in the cervical or thoracic region, they are almost invariably confined to the lumbar spine. The sites of the nuclear herniation seem to be determined by mechanical factors, for they are found in adults in the lower lumbar spine (Fig. 18) and in children in the upper lumbar spine (Figs. 25 and 26) in those parts of the spine which form the zenith of the spinal curve on flexion and which are therefore subjected to the greatest compressing force.

The effect of such a nuclear herniation has frequently been misinterpreted as a "persistent epiphysis." When the nuclear material escapes from the disc and passes through the thin cartilage plate at its junction with the epiphysial ring, the volume of the disc decreases and its function

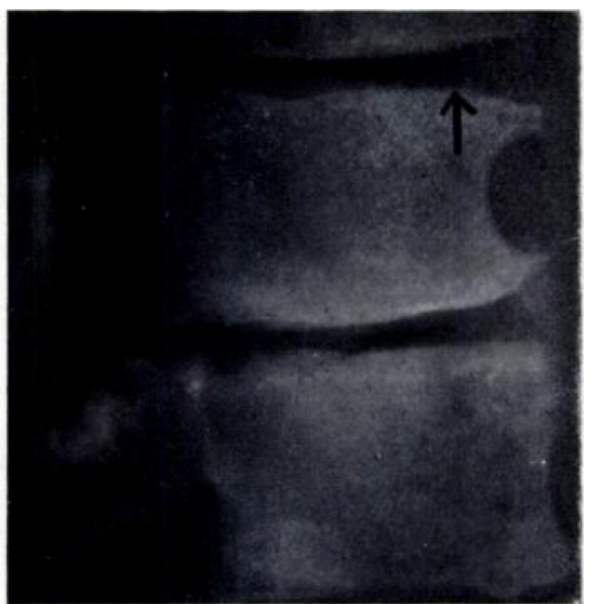

FIG. 16

Lateral radiograph of upper lumbar spine of man aged sixty years, showing radial spread of disc tissue outlined by the "vacuum phenomenon." 


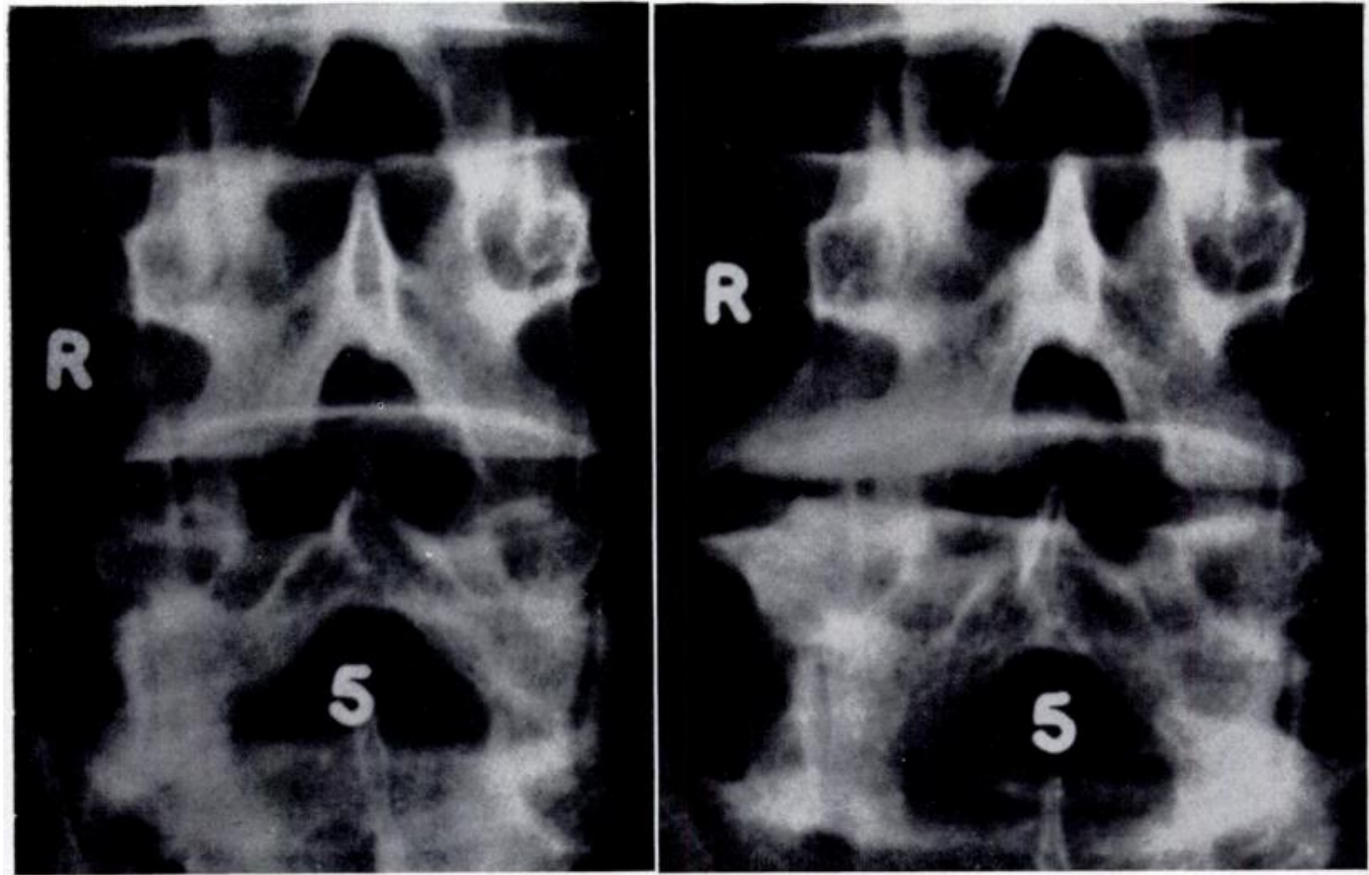

FIG. 17

Lumbar spine of man aged thirty-two years, showing the development of osteophytes around degenerative disc tissue. The time interval between the two radiographs is five years.

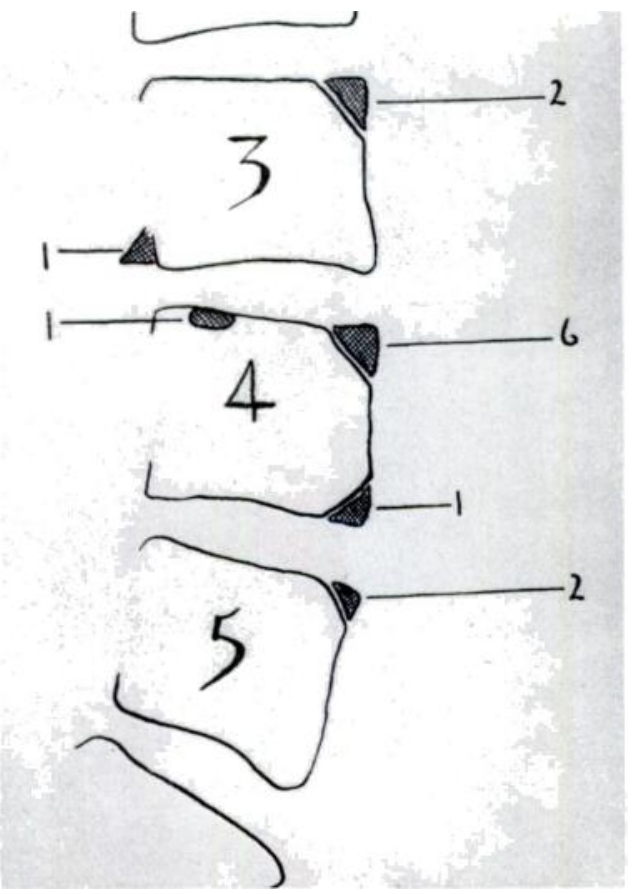

FIG. 18

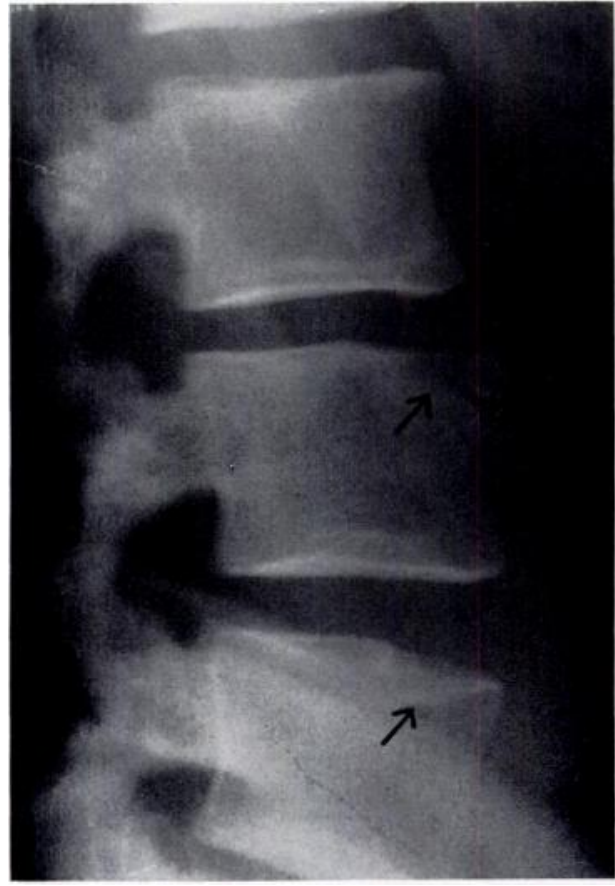

FIG. 19

Figure 18-Diagram showing sites of persistent epiphysis in ten consecutive cases. Figure 19-Lateral radiograph of lumbar spine in man aged twenty-seven years, showing anterior herniation of the nucleus pulposus into the centrum of L.4 and L.5 with the development of a "persistent epiphysis " at L.4 only. 


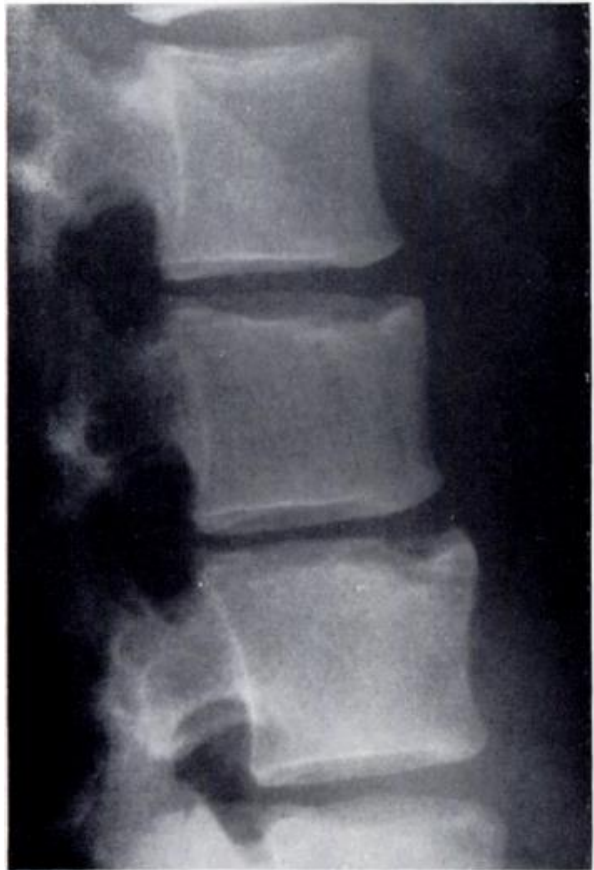

FIG. 20

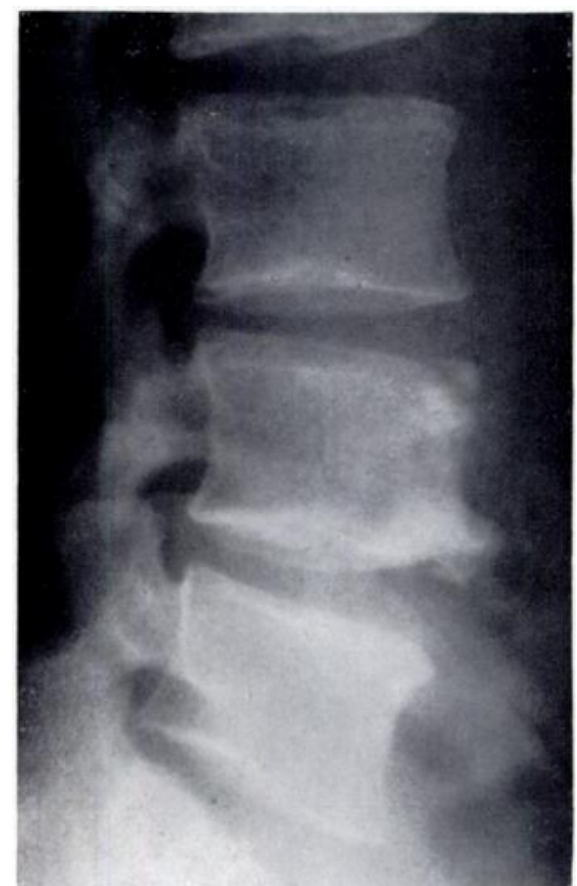

IFIG. 21

Figure 20-Lateral radiograph of the lumbar spine in woman aged twenty-three years, showing crescentic fragments separated from L.3 and L.4. Figure 21-I.ateral radiograph of lumbar spine in man aged thirty-one years, showing separation of the inferior as well as the superior margins of the centrum.

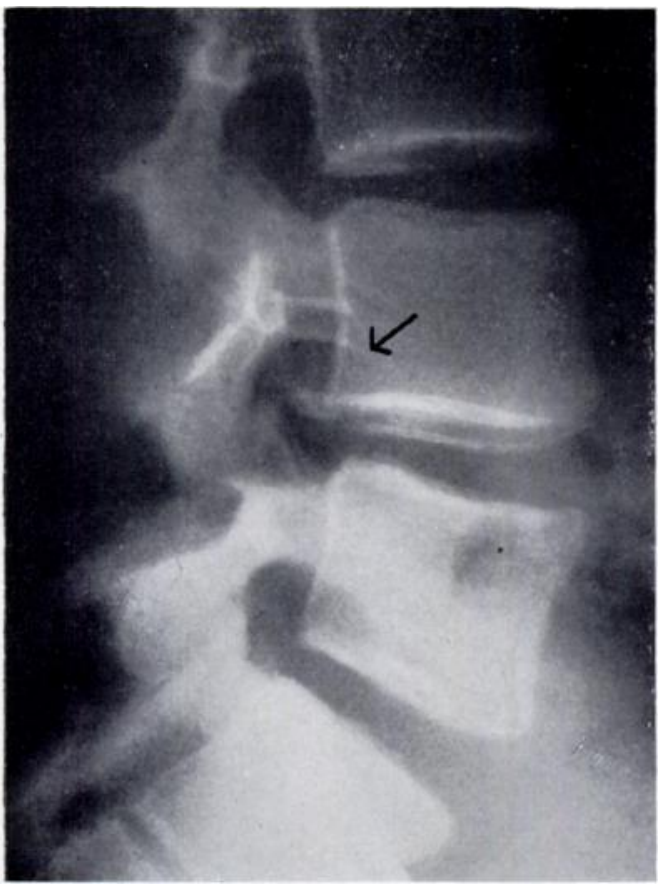

FIG. 22

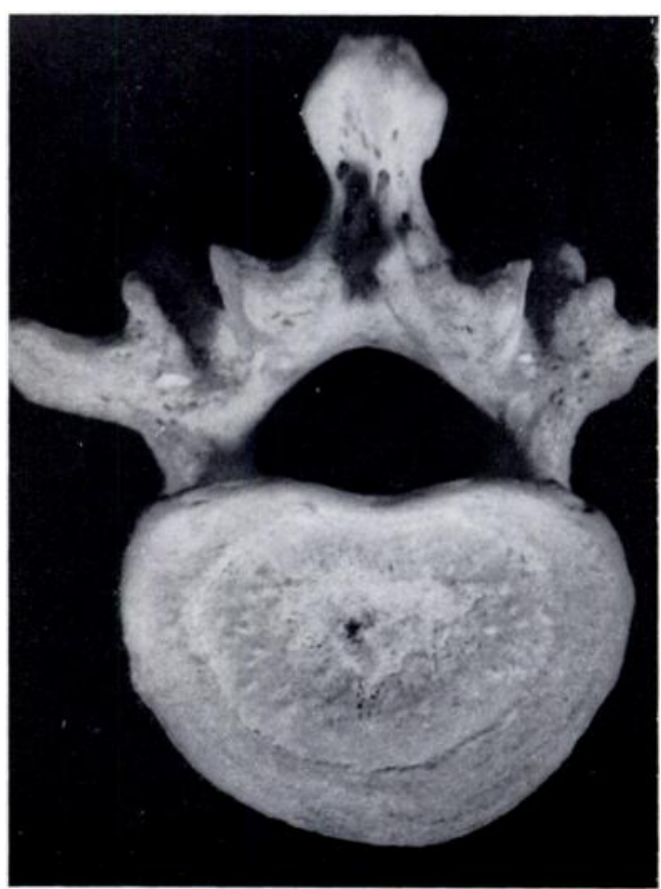

FIG. 23

Figure 22-Radiograph of lumbar spine in girl of twelve years, showing separation of the posterior portion of the epiphysial ring, which projects into the neural canal. Figure 23-Superior surface of lumbar vertebra, showing that the epiphysial ring completely encircles the centrum. Note site of typical Schmorl's node.

VOL. $36 \mathrm{~B}$, No. 2, MAY 1954 
is impaired, so that the stress on the anterior vertebral margins during flexion of the spine is increased. As the anterior part of the centrum is firmly fixed to the strong anterior longitudinal ligament and to the annulus, a crescentic piece of the vertebral body separates along the line of the nuclear herniation as a result of compressing

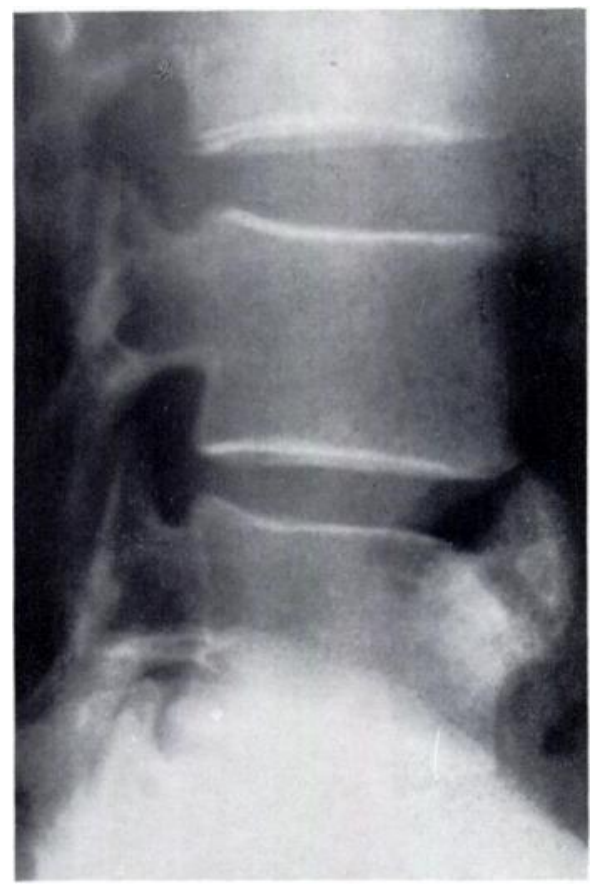

Fici. 24

Iateral radiograph of the lumbar spine in man ayed forty-one vears, showing proliferation of new bone at the site of anterior herniation of the nucleus beneath the epiphysial ring. strains (Fig. 19). The segment detached is almost invariably found lying within the limits of the anterior longitudinal ligament (Fig. 20) but sometimes it is the inferior margin of the centrum that separates (Fig. 21). Occasionally, however, the posterior part of the epiphysial ring may be affected (Fig. 2.2), for the epiphysial ring encircles the centrum and is not incomplete posteriorly as is often stated (Bradford and Spurling 1945, Armstrong 1952) (Fig. 2:3). These lesions therefore should be regarded more properly as pathological fractures of the centrum, and indeed sometimes a considerable proliferation of new bone is initiated (Fig. 24).

The symptoms produced are difficult to assess because of concomitant degenerative changes in the spine. However, there is no doubt that pain, backache, stiffness, and deformity of the spine may result, as in the following case, which illustrates not only the development of the "persistent epiphysis," but also how it may heal, leaving merely an anterior nuclear herniation into the spongiosa.

A child aged eleven years complained of a sudden stabbing pain in the lower thoracic region, radiating to the right renal area and lower abdomen. There was no history of injury. The pain recurred intermittently for two months, but the symptoms gradually subsided although she complained of pain in the back at intervals for the next four years. Serial radiography over this period showed the effect of a nuclear herniation beneath the epiphysial ring (Figs. 2.5 and 26 ).

These lesions should not be confused with marginal tuberculosis or with the calcification which occurs in the necrotic tears so commonly found in the anterior part of the annulus fibrosus (Figs. $2 \mathbf{2}$ and $2 \mathbf{2}$ ).

\section{HERNIATION OF THE NUGLEUS PULPOSUS THROUGH THE POSTERIOR SEGMENT OF THE ANNULUS}

Posterior protrusion of the intervertebral disc gives rise to a different, though now well recognised, clinical picture according to the level of the lesion. It is a result of disc degeneration and is most commonly found, therefore, at the junction of a mobile with a fixed part of the spine, where these changes most often occur. A normal disc does not prolapse.

The diagnosis of posterior disc protrusion should be a clinical one, but the site of the degeneration and therefore of the protrusion may often be indicated by plain radiography (Begg and Falconer 1949). Signs of localising value include narrowing of the disc space, hypertrophic or sclerotic changes of the opposing vertebral bodies, local scoliosis, relative displacement of the vertebral body, the "vacuum phenomenon," and, indirectly, sacralisation of the fifth lumbar vertebra in cases of sciatica. Signs indicating nerve root pressure may 
also be present. These include an alteration of the normal spinal curve (Figs. 29 and 30 ) and an abnormal pattern of movement (Fig. 31). In spines that appear normal on plain radiography

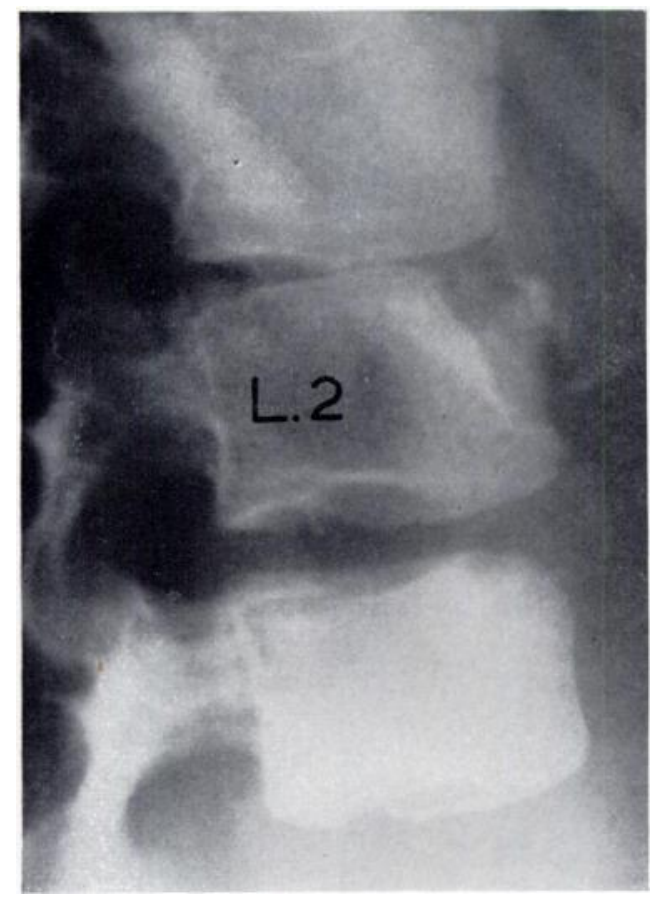

FIG. 25

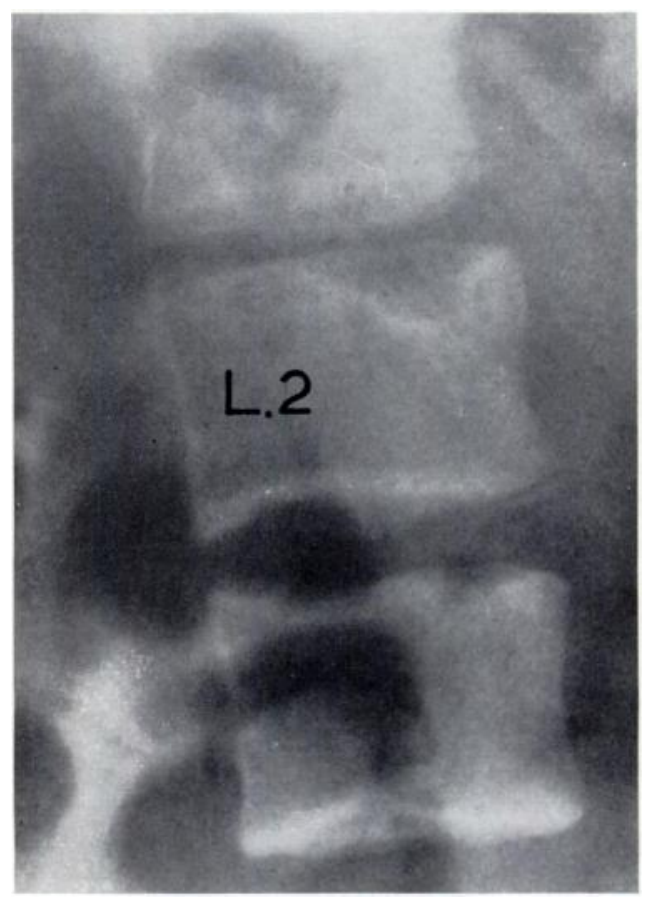

FIG. 26

Figure 25-Lateral radiograph of lumbar spine in girl aged thirteen vears. Note separation of the anterior part of the epiphysial ring of L.2, due to herniation of the nucleus beneath it. Figure 26-Four years later this separated part has united again with the centrum.

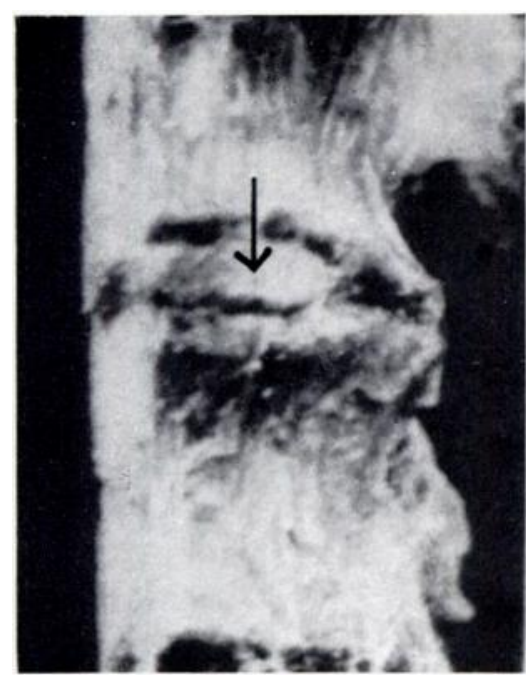

FIG. 27

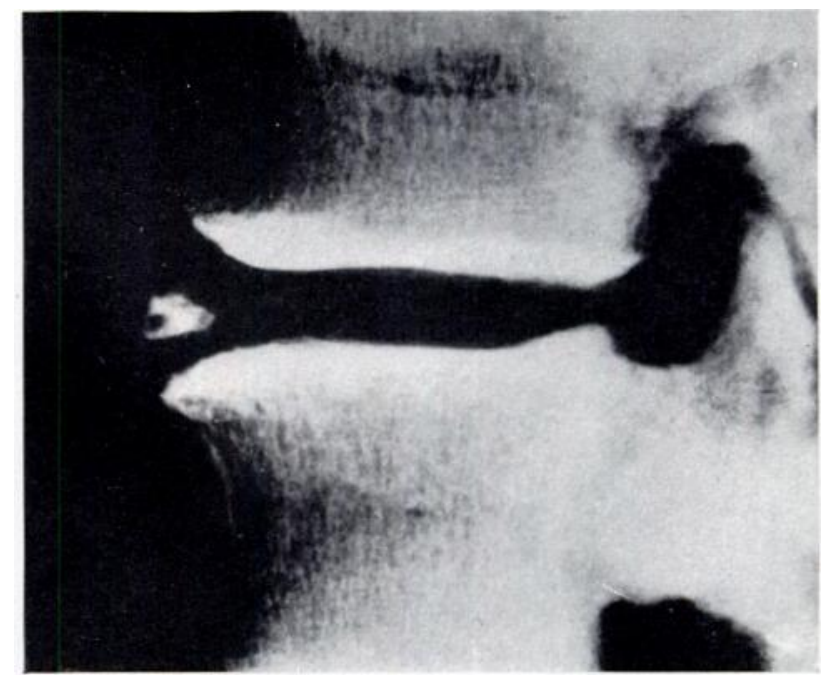

FIG. 28

Figure 27-Photograph of section of spine showing tỵpical ossification developing in necrotic areas in annulus fibrosus. Figure 28-Characteristic radiographic appearance.

and in those with widespread degeneration, plain radiography offers no help in localising the protrusion. Here, however, movement studies are often helpful in indicating the site of the lesion (Begg and Falconer 1949). It is important that this procedure should be carried

Vol. $36 \mathrm{~B}$, No. 2, MAY 1954 


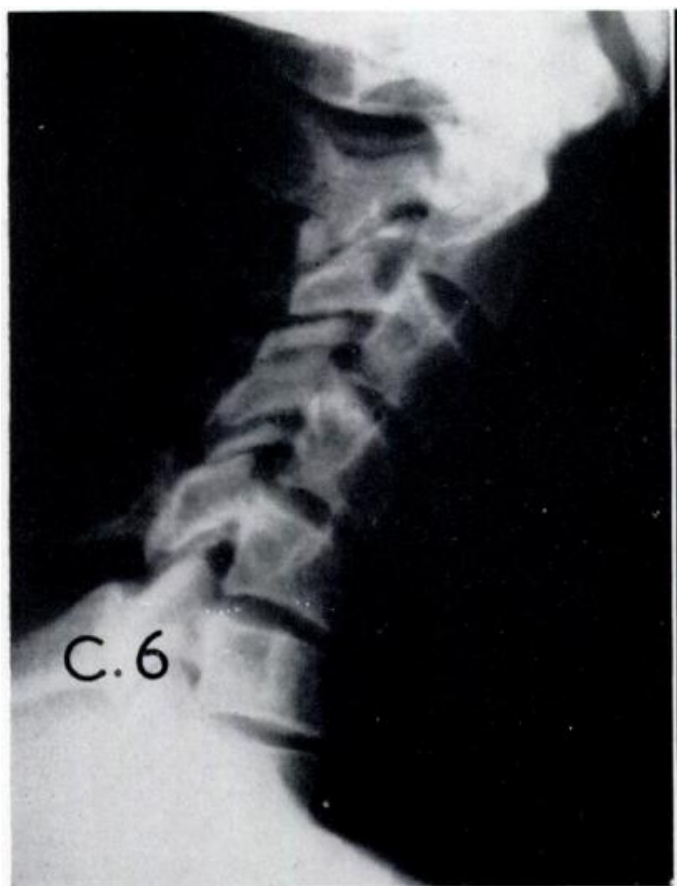

Fig. 29

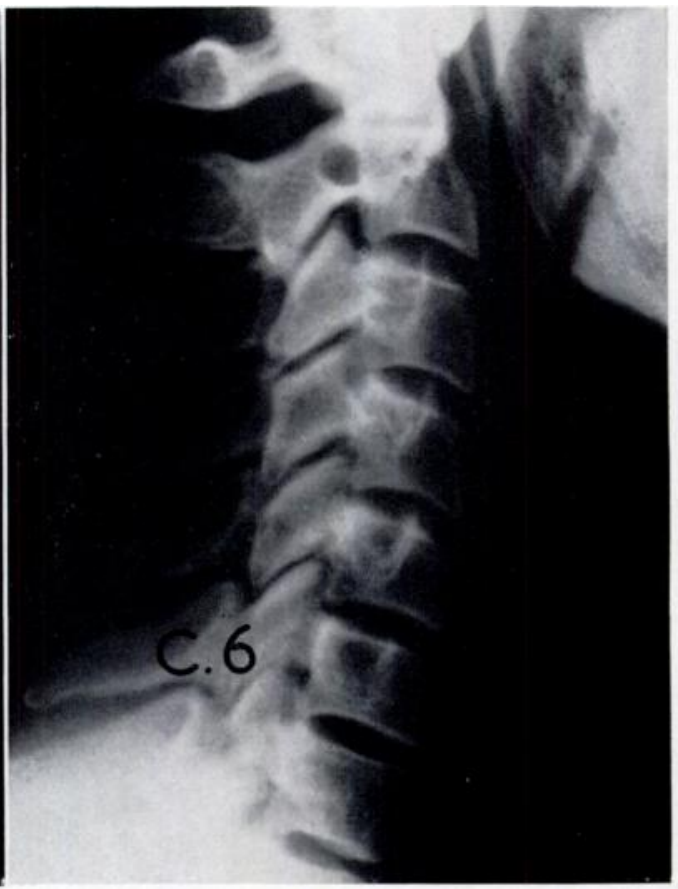

FIG. 30

Figure 29-Lateral radiograph of cervical spine of man aged forty-two years, showing reversal of normal curve due to a soft-tissue protrusion at the intervertebral disc between C.5 and C.6. Figure 30-I.ateral radiograph of the same patient after operative removal of the disc shows a return to the normal curve.

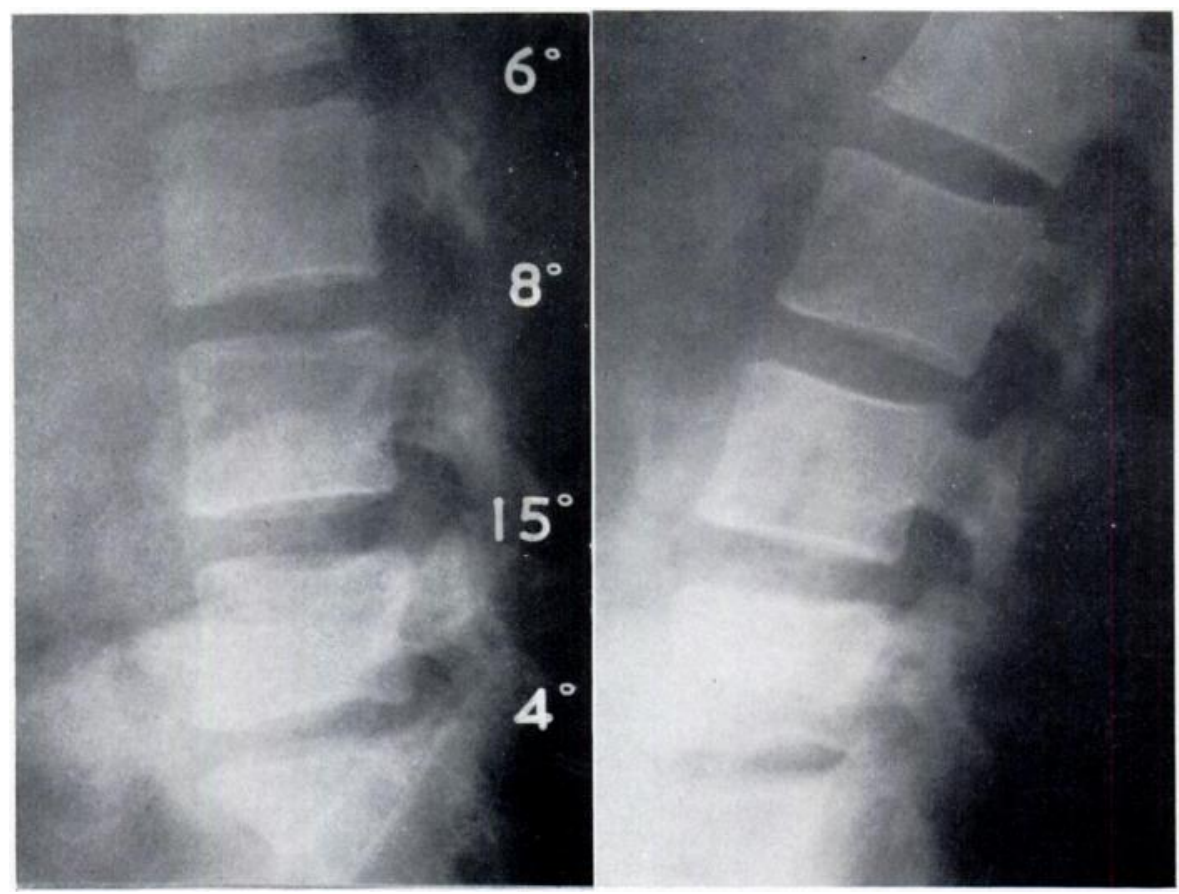

FIG. 31

Abnormal pattern of movement in the lumbar spine in woman aged forty-three years, showing relative restriction at $L .5$ intervertebral disc, where a protrusion was found at operation. 
out while pain is being experienced, for only then will the significant loss of movement from reflex muscle spasm be demonstrated at the level of the protrusion.

By myelography it is possible to distinguish four different types of herniation-projections, intermittent prolapses, extrusions and scarred discs (Begg, Falconer and Mccieorge 1946). It is of some interest to the surgeon to know beforehand which type of lesion he is likely to find at operation and how many protrusions are present. Myelography is a simple and harmless procedure which produces this additional information not otherwise available before operation in the great majority of cases. It should never be used as a substitute for a clinical diagnosis, for sometimes a disc protrusion observed incidentally at myelography causes no symptoms, and sometimes it produces symptoms only at intervals (Falconer, Mclieorge and Begg 1948).

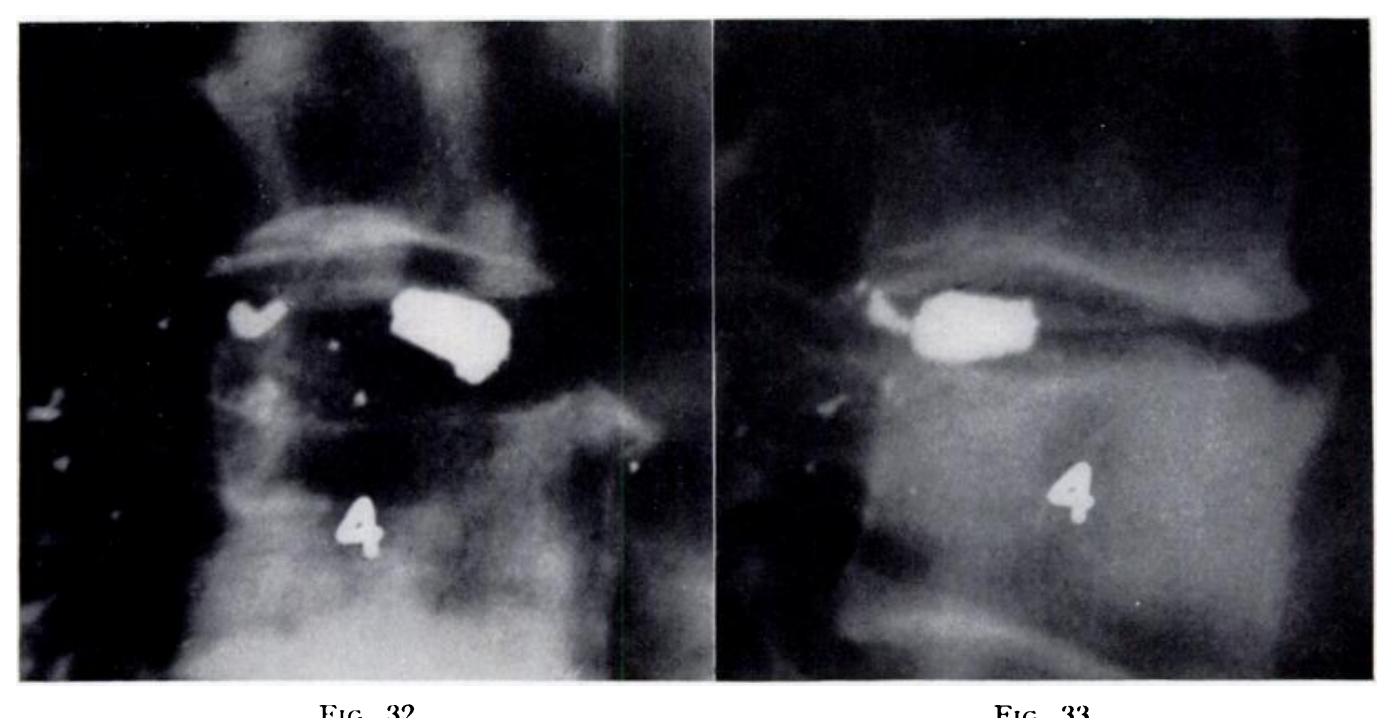

Figure 32-Lateral radiograph of man aged fifty-seven vears, showing bullet in the centre of the third lumbar intervertebral disc. Figure 33 - Radiograph taken fifteen months later showing how the bullet has moved backwards.

Projection-This is the commonest type of lesion; the degenerated nuclear tissue is gradually forced backwards and bulges the thin posterior fibres of the annulus, which remain intact over it. The mechanism of this is illustrated by the following case.

A man aged fifty-seven awoke in the early hours to find that his wife had shot him in the back. A lead bullet had lodged in the nucleus pulposus of his third lumbar intervertebral disc (Fig. 32). He suffered only a partial injury to the cauda equina and was soon walking again. Under the influence of daily activity the bullet moved backwards (Fig. 33).

Intermittent prolapse-The prolapse comes and goes according to the stresses affecting the spine. It becomes most marked on extension of the spine as seen at myelography (Figs. 34 and 35), but often disappears at operation when the patient is relaxed under anaesthesia and it is easily overlooked by the surgeon. These "concealed discs" (Dandy 1941) have done much to discredit the valuc of myelography but are, in fact, often more readily. demonstrated by this method than they are at operation.

Extrusion-Here the nuclear tissue extrudes from a small hole in the annulus, to form a cartilaginous nodule which has often been described as an ecchondroma. It may cause few symptoms in the lumbar region, as it is often freely movable, but, like other protrusions in the thoracic region, may do serious harm as in the following case in which a fatal transverse myelitis resulted.

A man aged fifty-nine " ricked" his back while lifting heavy logs on to a lorry. He felt

VOL. $36 \mathrm{~B}$, พO. 2 , MAY 1954 
a sudden severe pain in the back and had difficulty in straightening it. He was able to carry on his work as a plumber for the next six weeks, but then, on catching an empty kerosene tin

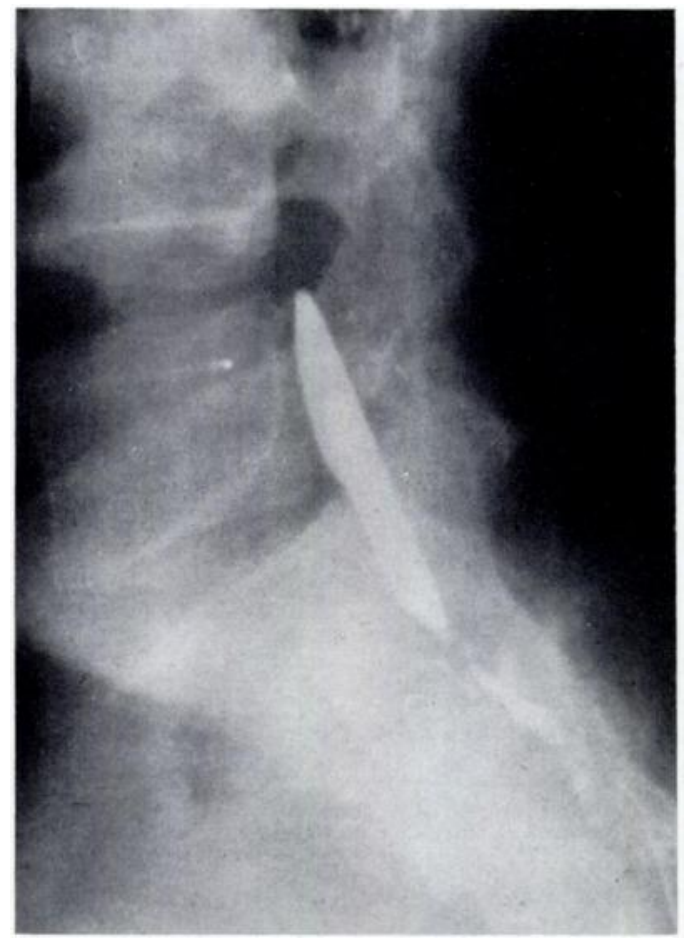

FIG. 34

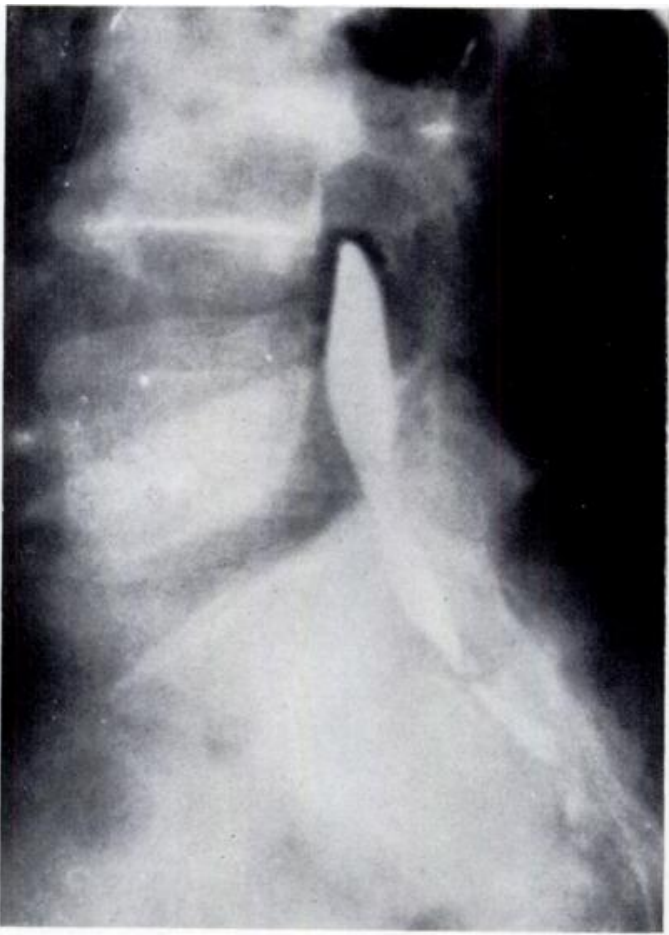

FIG. 35

Myelograms of man aged thirty-six taken with the patient lying prone on the radiographic table (Fig. 34) and lying prone with back hyperextended (Fig. 35). Note extrusion backwards of intermittent protrusion and projection forwards of the relaxed ligamentum flavum.

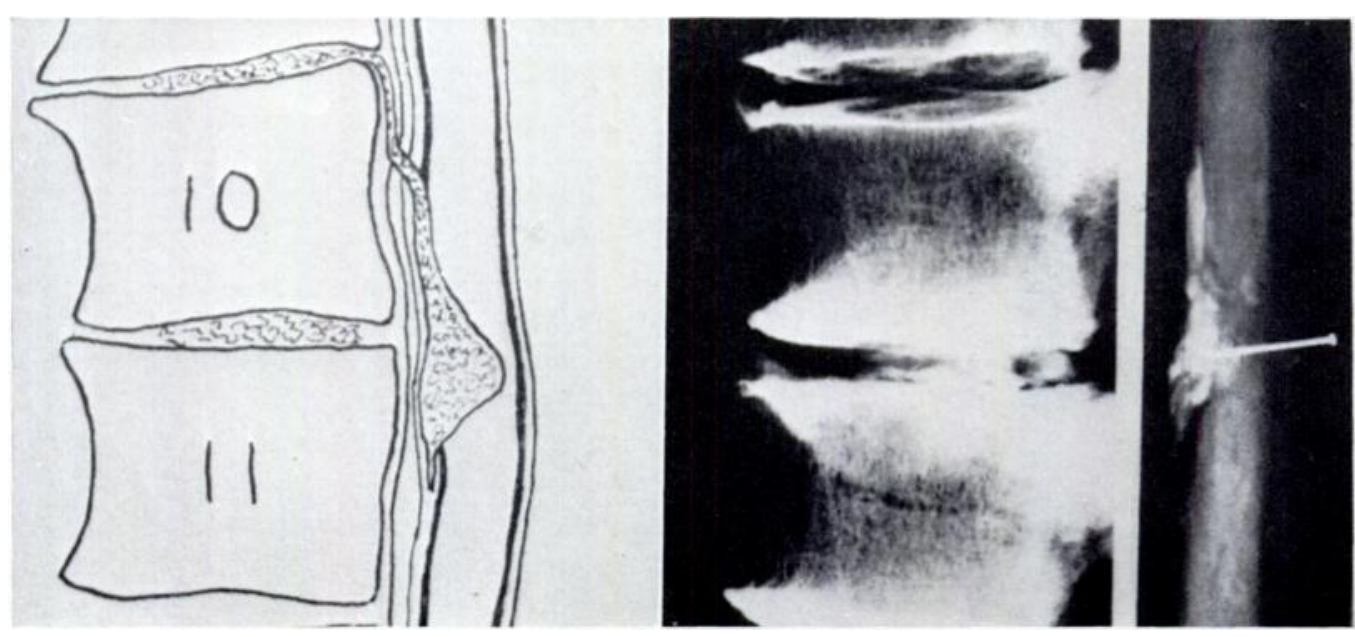

FIG. 36

I ateral radiograph of thoracic spine and spinal cord, with explanatory diagram, in man aged fifty-nine years, showing the effect of herniation of nuclear material from the intervertebral disc between T.9 and T.10 into the spinal cord.

thrown to him by a workmate, felt a " click" in his back and developed a gradual paralysis of his legs and loss of sphincter control over the next two days. A diagnosis of transverse myelitis was made. He died four months later from urinary infection. The real cause of his 
symptoms was a herniation of nuclear tissue from the ninth thoracic intervertebral disc, which burst through a small perforation in the posterior surface of the annulus, tracked caudally and ruptured through the posterior longitudinal ligament and the meninges to become embedded in the spinal cord. During his four months in bed the herniated nuclear material calcified (Fig. 36).

Scarred disc-Here the protrusion has been absorbed over the years, but the nerve roots remain anchored to the posterior part of the disc, which does not now herniate. In these cases, no abnormality may be noted on myelography except, perhaps, evidence of arachnoiditis. This, taken in conjunction with findings during plain radiography, indicates the type of lesion.

It will be seen, therefore, that degeneration of the intervertebral disc with its resultant herniation of the nucleus pulposus into the structures that surround it presents many different clinical problems and difficulties in diagnosis. An understanding of the significance of the radiological manifestations of these lesions and a careful correlation with the clinical features of the case are necessary in order to make an accurate diagnosis.

\section{SUMMARY}

1. As a result of degenerative changes in the intervertebral disc, nuclear tissue often herniates through its confining structures. These lesions are common, even in children, and often lead to difficulty in diagnosis.

2. The radiological manifestations of nuclear herniations into the spongiosa of the vertebral body, through the anterior part of the annulus fibrosus, beneath the epiphysial ring, and through the posterior part of the annulus are described and illustrated. The clinical significance of these radiological appearances and their pathological basis is indicated.

3. An understanding of the significance of the radiological findings in herniation of the nucleus pulposus and a careful correlation with the clinical features of the case are necessary for accurate diagnosis.

I am grateful to those medical and surgical colleagues who have referred to me for investigation patients under their care, and who have made available to me their clinical records. I am indebted to Professor N. W. Nisbet for help and encouragement in the preparation of this paper.

\section{REFERENCES}

Armstrong, J. R. (1952): Lumbar Disc Lesions; Pathogenesis and Treatment of Low Back Pain and Sciatica. Edinburgh and London: E. \& S. Livingstone Ltd.

Batts, M., Jun. (1939): Rupture of the Nucleus Pulposus; Anatomical Study. Journal of Bone and Joint Surgery, 21, 121.

BegG, A. C., and Falconer, M. A. (1949): Plain Radiography in Intraspinal Protrusion of Lumbar Intervertebral Disks: a Correlation with Operative Findings. British Journal of Surgery, 36, 225.

Begg, A. C., FAlconer, M. A., and McGeorge, M. (1946): Myelography in Lumbar Intervertebral Disk Lesions. British Journal of Surgery, 34, 141.

Bradford, F. K., and SpURling, R. G. (1945): The Intervertebral Disc: with Special Reference to Rupture of the Annulus Fibrosus with Herniation of the Nucleus Pulposus. Springfield, Illinois: Charles C. Thomas. Coventry, M. B., Ghormley, R. K., and Kernohan, J. W. (1945) : The Intervertebral Disc: Its Microscopic Anatomy and Pathology. Part III. Pathological Changes in the Intervertebral Disc. Journal of Bone and Joint Surgery, 27, 460.

DANDY, W. E. (1941) : Concealed Ruptured Intervertebral Disks; a plea for Elimination of Contrast Mediums in Diagnosis. Journal of the American Medical Association, 117, 821.

FAlconer, M. A., McGeorge, M., and BegG, A. C. (1948): Observations on the Cause and Mechanism of Symptom-Production in Sciatica and Low-Back Pain. Journal of Neurology, Neurosurgery and Psychiatry, 11, 13.

vol. 36 B, No. 2, MAY 1954 